\title{
Radiograf idiopathic osteosclerosis gigi molar ketiga impaksi pada Cone Beam Computed Tomography
}

\author{
Anak Agung Gde Dananjaya Agung ${ }^{1 *}$, Ni Ketut Ayu Lestarini²
}

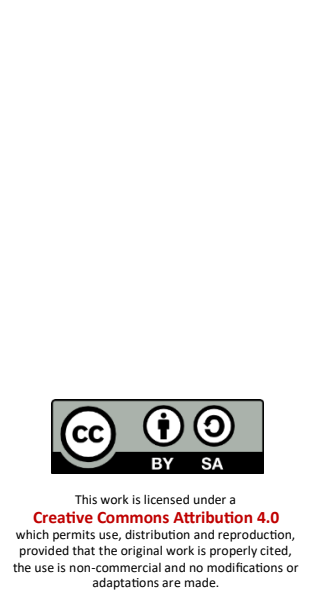

ABSTRACT

Objectives: To analyze idiopathic osteosclerosis radiographs associated with impacted third molars (M3) on cone beam computed tomography (CBCT).

Case Report: A 36-year-old woman came to the Dentology Clinic complaining that the right mandibular third molar area often felt sore. The patient was referred for CBCT examination and incidentally, a radiopaque image with clear boundaries, irregular shape was found on the periapical impacted third molar without caries in the tooth crown. The treatment plan that will be carried out on the tooth is extraction.

Conclusion: Idiopathic osteosclerosis lesions are lesions that occur in vital teeth that have the characteristics of a well-defined radiopaque appearance and are asymptomatic. Characteristics of idiopathic osteosclerosis lesions can be visualized by $C B C T$ well. $C B C T$ has the advantage of being able to display a detailed picture of the lesion in three dimensions (3D) with a fairly good image resolution.

\section{Keywords: Cone beam computed tomography, Idiopathic osteosclerosis, Impacted third molar} Cite this article: Dananjaya Agung AAG, Lestarini NKA. Radiograf idiopathic osteosclerosis gigi molar ketiga impaksi pada Cone Beam Computed Tomography. Jurnal Radiologi Dentomaksilofasial Indonesia 2021;5(1)17-22. https:// doi.org/10.32793/jrdi.v5i1.679

\section{INTRODUCTION}

Idiopathic osteosclerosis (IO) merupakan sklerosis atau deposisi tulang yang terletak di dalam tulang (intrabony), yang ditandai dengan gambaran radioopak, tidak disertai adanya inflamasi, neoplastik, atau penyakit sistemik. ${ }^{1-3}$ Idiopathic osteosclerosis juga disebut dengan istilah enostosis, dense bone island, focal periapical osteopetrosis, bone whorl, eburnated bone, focal osteosclerosis, bone whorl, atau bone scar. Etiologi dari idiopathic osteosclerosis tidak diketahui secara pasti, namun reaksi tulang berupa lesi ini, seringkali dikaitkan dengan adanya peningkatan tekanan oklusal, fragmen sisa akar, peningkatan aliran darah lokal, dan variasi anatomi. Idiopathic osteosclerosis terkadang ditemukan secara tidak sengaja (insidental) saat melakukan pemeriksaan radiografi. Sebagian besar dari lesi idiopathic osteosclerosis tidak menunjukkan gejala (asimptomatik). ${ }^{2-5}$ Idiopathic osteosclerosis lebih sering terjadi $\mathrm{di}$ rahang bawah dibandingkan rahang atas terutama pada area gigi premolar dan gigi molar, serta dapat terjadi pada apikal gigi, diantara akar, atau jauh dari gigi. Kejadian idiopathic osteosclerosis pada rahang, tidak berkaitan atau berhubungan dengan ras maupun jenis kelamin. Beberapa literature mengatakan bahwa idiopathic osteosclerosis lebih banyak dialami oleh wanita dibandingkan laki$\mathrm{laki}^{3,6}$ namun beberapa penelitian menunjukkan bahwa tidak terdapat perbedaan yang signifikan terkait insiden lesi idiopathic osteosclerosis antara wanita dan laki-laki. ${ }^{7-9}$ Idiopathic osteosclerosis lebih sering ditemukan pada orang dewasa dibandingkan pada anak-anak, dan terbanyak pada usia dekade ketiga yaitu usia 17-70 tahun. ${ }^{10}$

Dalam sebuah radiograf, idiopathic osteosclerosis berbentuk bulat atau tidak beraturan (irregular) dengan ukuran yang bervariasi mulai dari diameter $2 \mathrm{~s} / \mathrm{d} 3 \mathrm{~mm}$ hingga $1 \mathrm{~s} / \mathrm{d} 2 \mathrm{~cm}$, dan lesi dapat menjadi sangat besar hingga seukuran rahang. Idiopathic osteosclerosis memiliki batas tepi yang jelas (well-defined), dan terkadang menyatu dengan tulang trabekula disekitarnya. ${ }^{2,3,11}$ Sebagian gambaran radiografi idiopathic osteosclerosis terlihat adanya tepi radiolusen atau kapsul dan berbatasan langsung dengan tulang. Struktur internal idiopathic osteosclerosis biasanya tanpa adanya pola khas namun tergantung dari bentuk dan ketebalannya, dan pada kasus tertentu terkadang ditemukan gambaran radiolusen disekitar lesi. Efek pada struktur dan jaringan sekitar lesi, terutama pada daerah periapikal dari akar gigi dapat mengakibatkan resorbsi akar eksternal, dapat menghambat erupsi gigi, serta menggeser gigi disebelahnya. ${ }^{2,6,12}$ Beberapa penelitian menjelaskan bahwa $20 \%$ dari kasus idiopathic osteosclerosis pada rahang tidak memiliki hubungan dengan gigi, akan tetapi dari beberapa penelitian ditemukan bahwa idiopathic osteosclerosis dapat menyebabkan gigi disekitarnya impaksi, periodontal ligament space (PDLS) 
terputus, dan tidak terdeteksinya batas dari akar gigi. Idiopathic osteosclerosis tidak menimbulkan rasa nyeri karena bersifat asimptomatik dan gig disekitarnya masih tetap vital. ${ }^{1,4,13}$ Lesi ini dominan merupakan lesi tunggal (single) akan tetap terkadang terdapat dalam beberapa kasus menunjukkan lesi multiple. ${ }^{13}$

Tujuan penulisan laporan kasus ini adalah untuk menganalisis radiograf idiopathic osteosclerosis yang berhubungan dengan gigi molar ketiga (M3) impaksi pada cone beam computed tomography (CBCT). Idiopathic osteosclerosis lebih sering ditemukan pada gigi premolar atau molar pertama rahang bawah. Kasus yang dilaporkan pada laporan kasus ini merupakan kasus yang terbilang cukup jarang terjadi dikarenakan kasus idiopathic osteosclerosis ditemukan pada gigi molar ketiga impaksi rahang bawah.

\section{CASE REPORT}

Seorang wanita berusia 36 tahun datang dengan keluhan adanya rasa linu pada daerah belakang kanan bawah tepatnya di area molar ketiga (M3) yang tampak belum erupsi Pemeriksaan klinis menunjukkan tidak terlihat adanya tanda peradangan, saat palpasi pasien tidak merasa nyeri, tes dingin negative (-) dan tes perkusi negative (-). Gigi tersebut diduga impaksi karena tidak ada riwayat pencabutan gigi pada area tersebut. Pasien kemudian dirujuk untuk dilakukan pemeriksaan radiografi cone beam computed tomography (CBCT).

Hasil pemeriksaan CBCT terlihat bawah gigi 48 (gigi molar ketiga kanan bawah) tertanam didalam tulang atau impaksi, dan tidak dapat erupsi secara sempurna meskipun terdapat ruang yang cukup. Pandangan koronal didapatkan gigi impaksi disertai gambaran radioopak berbatas jelas dengan bentuk tidak beraturan (irregular) di daerah periapikal gig 48 dengan ukuran lebar lingual - bukal lesi 5,52 mm serta dari jarak puncak ke dasar lesi $9,58 \mathrm{~mm}$. Pandangan sagital terlihat gigi impaksi 48 disertai gambaran lesi radioopak, berbatas jelas, berbentuk tidak beraturan (irregular) di daerah periapikal gigi 48 dengan lebar 12,10 mm (mesial - distal) dan puncak ke dasar lesi 9,62 mm, lesi terlihat meluas dari cemento enamel junction (CEJ) mesial ke distal. Pandangan aksial didapatkan gambaran radioopak berbatas jelas, bentuk tidak beraturan (irregular) pada daerah periapikal pada gigi 48 dengan ukuran bukal - lingual 7,08 mm dan mesial - distal 13,23 $\mathrm{mm}$.

\section{DISCUSSION}

Kasus idiopathic osteosclerosis sering dijumpai pada regio posterior, hal ini sesuai dengan temuan yang didapatkan pada penelitian yang dilakukan oleh Demir dan Pekiner (2019) yang menemukan bahwa idiopathic osteosclerosis berlokasi signifikan lebih tinggi pada region molar rahang bawah (30.4\%). ${ }^{2}$ Penelitian serupa juga menunjukkan bahwa idiopathic osteosclerosis paling banyak terjadi pada rahang bawah dan hanya beberapa kasus pada rahang atas, dan paling banyak berlokasi di regio posterior. ${ }^{7}$ Hal tersebut dikarenakan terdapat superposisi struktur anatomi yang membuat lesi pada rahang atas sulit untuk dideteksi menggunakan radiografi khususnya radiografi panoramik dibandingkan pada rahang bawah. Selain itu, rahang bawah memiliki densitas tulang yang tinggi, memiliki tekanan mastikasi yang lebih besar khususnys pada daerah posterior, serta resorpsi akar yang tertinggal dari gigi molar sulung yang disertai deposisi tulang juga dapat berkontribusi sebagai penyebab munculnya idiopathic osteosclerosis lebih sering pada rahang bawah khususnya regio posterior. ${ }^{3}$ Penemuan kasus idopathic osteosclerosis pada gigi 48 (gigi molar ketiga kanan bawah) jarang terjadi, biasanya lesi ini terjadi pada gigi molar dan premolar rahang bawah,
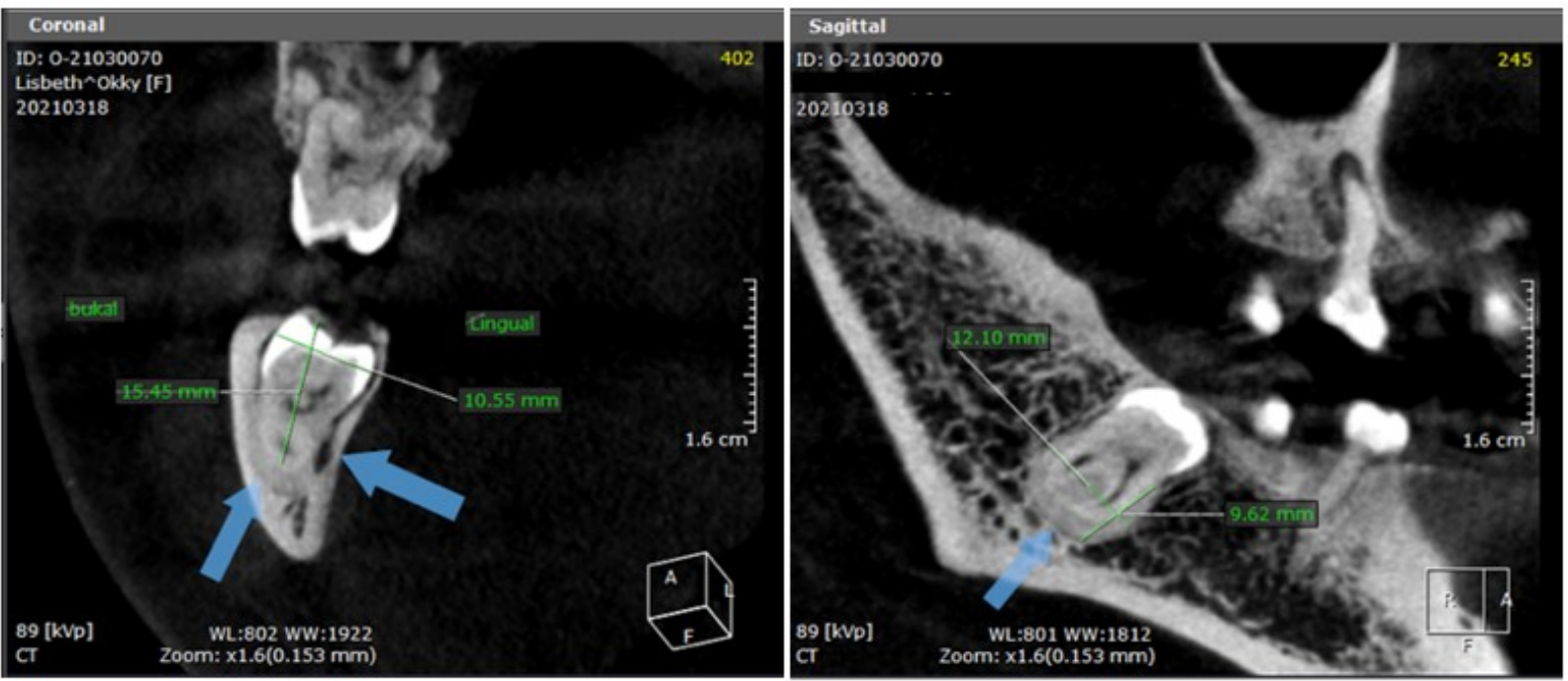

Gambar 1. Tampilan koronal (kiri) dan tampilan sagittal (kanan) pada pemeriksaan radiografi CBCT 

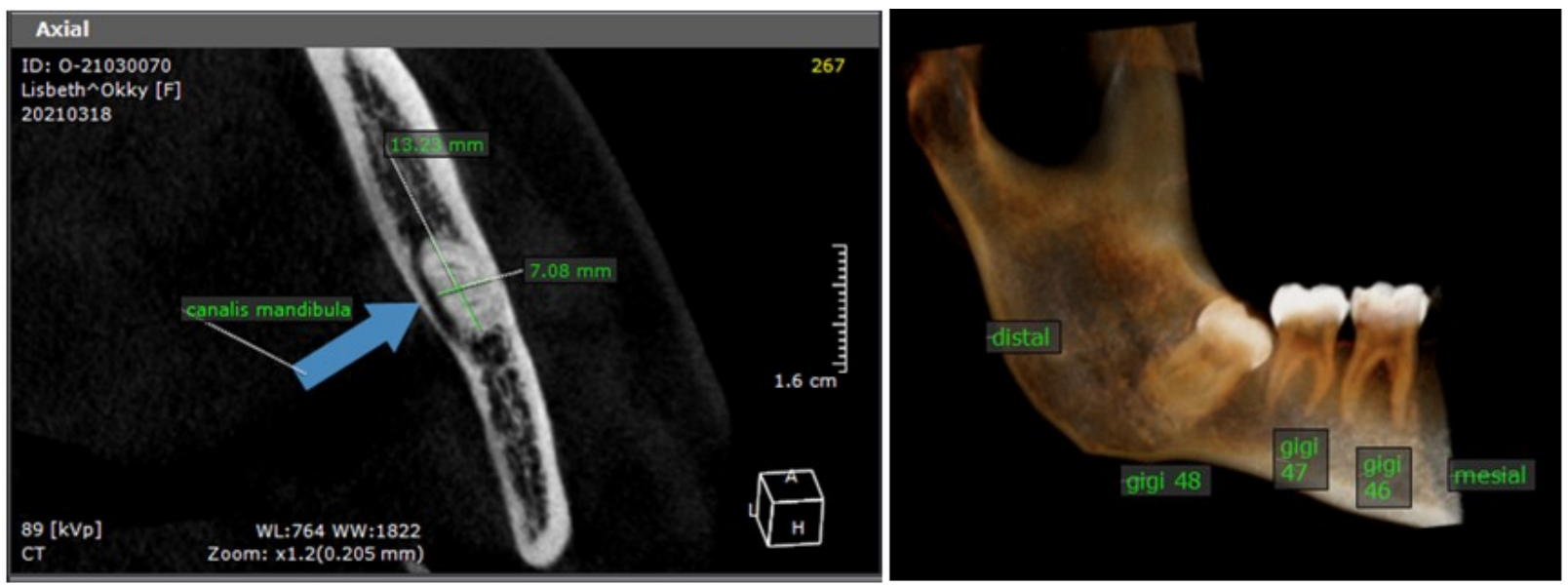

Gambar 2. Tampilan aksial pada pemeriksaan CBCT (kiri), tampilan 3D (kanan)

khususnya molar pertama rahang bawah. ${ }^{2,9} \mathrm{Hal}$ tersebut dikarenakan area gigi premolar rahang bawah dekat dengan foramen mentalis sehingga rahang bawah menerima supplai darah yang cukup untuk membentuk massa tulang. ${ }^{7}$ Selain itu, frekuensi lesi pada gigi premolar rahang bawah dapat dikaitkan dengan sisa akar premolar dan pergantian dengan tulang sklerotik. ${ }^{6}$ Penelitian yang dilakukan oleh Misirlioglu dkk (2013) mendapatkan hasil yaitu hubungan lesi idiopathic osteosclerosis dengan gigi paling banyak berada terjadi pada bagian apikal, kemudian interradicular. ${ }^{7}$ Hasil serupa juga ditemukan pada penelitian yang dilakukan oleh Montes dkk (2018). ${ }^{14}$ Kasus lesi idiopathic osteosclerosis yang dilaporkan ditemukan pada daerah periapikal gigi molar ketiga impaksi.

Beberapa literature menyatakan bahwa kasus idiopathic osteosclerosis lebih banyak ditemukan pada wanita dibandingkan laki-laki, hal serupa juga ditemukan oleh penelitian yang dilakukan oleh Farhadi dkk (2016) dan Gamba dkk (2021). Namun belum dijelaskan mengenai alasan wanita lebih sering mengalami lesi idiopathic osteosclerosis dibandingkan laki-laki. Penelitian yang dilakukan oleh Zayet dan Hasan (2019) menunjukkan hasil bahwa persentase wanita dan laki-laki yang mengalami idiopathic osteosclerosis memiliki hasil yang hampir sama yaitu $16,6 \%$ pada wanita dan $16,9 \%$ pada laki-laki. ${ }^{10}$ Hasil serupa juga ditemukan pada penelitian yang dilakukan oleh Misirlioglu dkk
(2013), Sisman dkk (2011), dan Azizi dkk (2017) yang menunjukkan bahwa tidak terdapat perbedaan yang signifikan terkait insiden lesi idiopathic osteosclerosis antara wanita dan lakilaki. ${ }^{7-9}$ Kasus lesi idiopathic osteosclerosis yang dilaporkan dialami oleh seorang wanita berusia 36 tahun.

Beberapa penelitian melaporkan usia yang paling sering mengalami idiopathic osteosclerosis adalah usia 9 tahun dan penelitian melaporkan bahwa idiopathic osteosclerosis paling sering terdeteksi pada usia 20-29 tahun dan 30-39 tahun. ${ }^{2}$ Beberapa penelitian lainnya menunjukkan bahwa idiopathic osteosclerosis ditemukan pada rentang usia 17-70 tahun. Hal tersebut dikarenakan lesi idiopathic osteosclerosis bersifat asimptomatik sehingga lesi terlambat untuk terdeteksi. ${ }^{10}$ Penelitian yang dilakukan oleh Ledesma-Montes dkk (2018) mendapatkan hasil bahwa idiopathic osteosclerosis dapat terjadi pada usia dekade pertama hingga ketiga. Ukuran lesi akan meningkat pada rentang usia 7-30 tahun dan akan menurun pada usia lebih lanjut. Hal tersebut dikarenakan lesi idiopathic osteosclerosis terjadi pada masa pertumbuhan dan usia dewasa, dan pada masa tersebut densitas tulang dalam kondisi yang baik. ${ }^{14}$

Beberapa literature menyebutkan bahwa idiopathic osteosclerosis merupakan bentuk variasi anatomis dari perkembangan intraosseus dan seharusnya berada pada klasifikasi yang berbeda
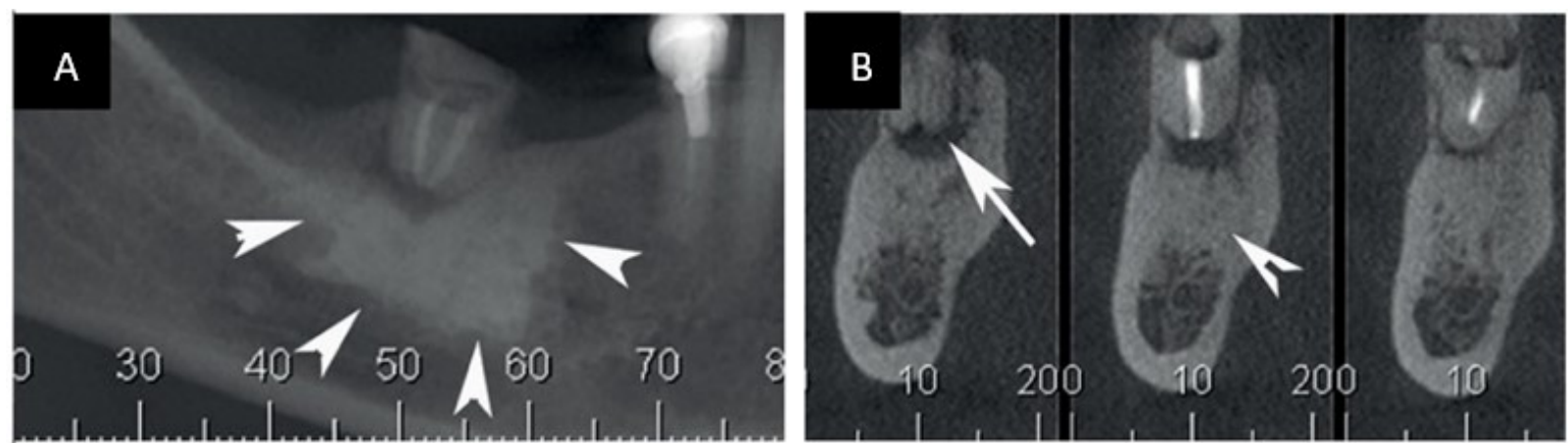

Gambar 3. Condensing osteitis pada pemeriksaan radiografi CBCT terlihat A. lesi diffuse berbatas tidak jelas, B. terdapat lesi periapikal ${ }^{17}$ 
dengan lesi radioopak akibat adanya inflamasi, proses displasia, manifestasi penyakit sistemik, neoplasma, dan berhubungan dengan beberapa perluasan lesi ke arah kortikal. ${ }^{8,15}$ Lesi idiopathic osteosclerosis secara mekanisme penyakit merupakan lesi dengan pertumbuhan terlokalisir dari tulang kompakta dalam struktur tulang trabekular atau kanselus sehingga terjadi pelebaran tulang trabekular dan meluas hingga ke ruang medular dan kemunculan lesi idiopathic osteosclerosis bersifat sklerotik soliter. ${ }^{16}$ Gambaran radiografi lesi pada kasus yang dilaporkan adalah radioopak dengan batas jelas dengan bentuk tidak beraturan (irregular), hal tersebut serupa dengan gambaran radiografi yang didapatkan pada penelitian yang dilakukan oleh Farhadi dkk (2016) yang menemukan bahwa bentuk idiopathic osteosclerosis yang paling banyak adalah irregular yaitu sebanyak $40,6 \%$ dan diikuti dengan bentuk oval sebanyak $31,3 \%$, dan bentuk yang paling sedikit ditemukan adalah bentuk bulat yaitu sebanyak $28,1 \% .{ }^{6} \mathrm{Hal}$ serupa juga ditemukan pada beberapa penelitian yang menunjukkan bahwa lesi idiopathic osteosclerosis paling banyak berbentuk irregular dan diikuti dengan lesi berbentuk bulat., Pada kasus idiopathic osteosclerosis yang dilaporkan oleh Gamba dkk (2020), dalam radiografi panoramik idiopathic osteosclerosis berbentuk oval ditemukan di regio anterior dan bentuk oval dan sinuous pada regio molar dengan tulang trabekular yang irregular, sedangkan pada region anterior dengan pola regular. ${ }^{3}$ Berdasarkan pencarian kepustakaan yang dilakukan oleh penulis, belum terdapat literature yang menjelaskan mengenai faktor-faktor yang dapat menentukan atau mempengaruhi bentuk-bentuk lesi idiopathic osteosclerosis.

Diagnosis banding untuk idiopathic osteoscleoris adalah periapical osseous dysplasia (POD), periapical sclerosing osteitis atau condensing osteitis, hipersementosis, benign cementoblastoma, sialolithiasis, aneurysmal bone cyst, osteogenic sarcoma, torus mandibularis, eksostosis dan multiple myeloma yang disertai dengan osteosclerosis. ${ }^{5,12}$ Pada periapical osseous dysplasia terdapat gambaran radioopak yang dibatasi
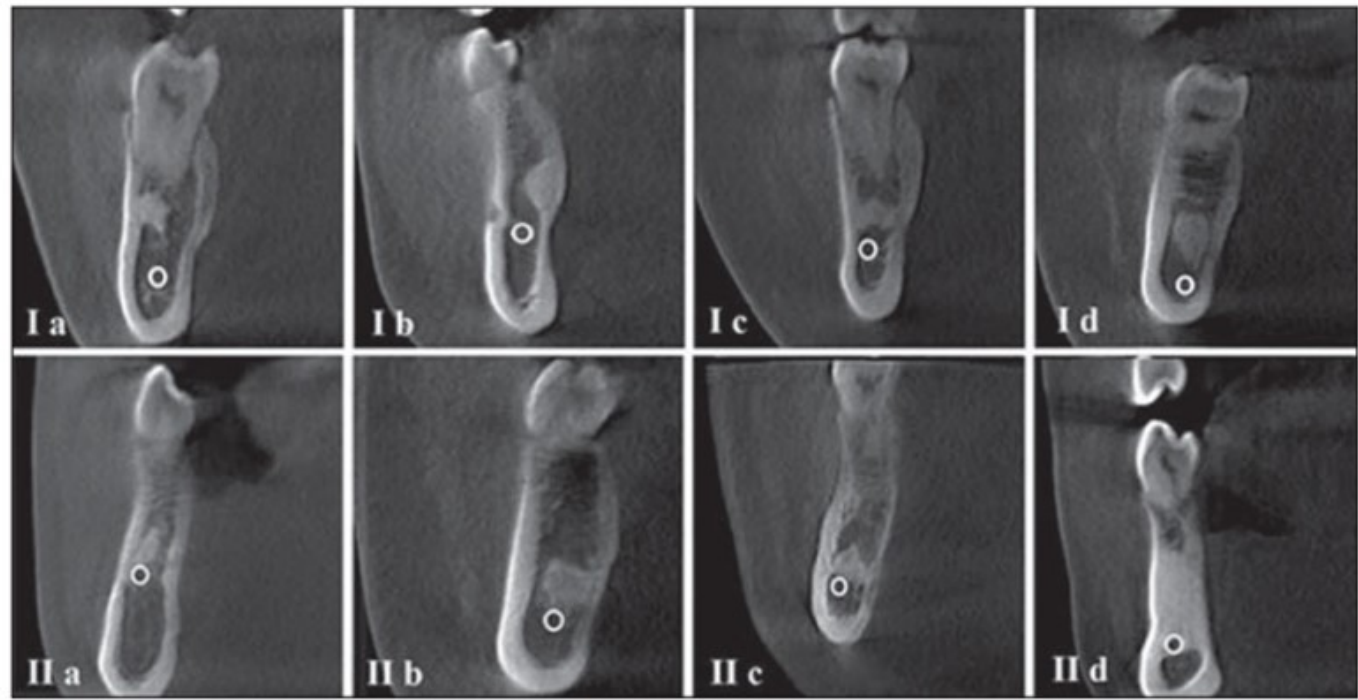

Gambar 4. Perbedaan tipe lesi idiopathic osteosclerosis pada tampilan koronal pada radiografi CBCT menunjukkan tidak terdapat pelebaran pada tulang kortikal $^{7}$
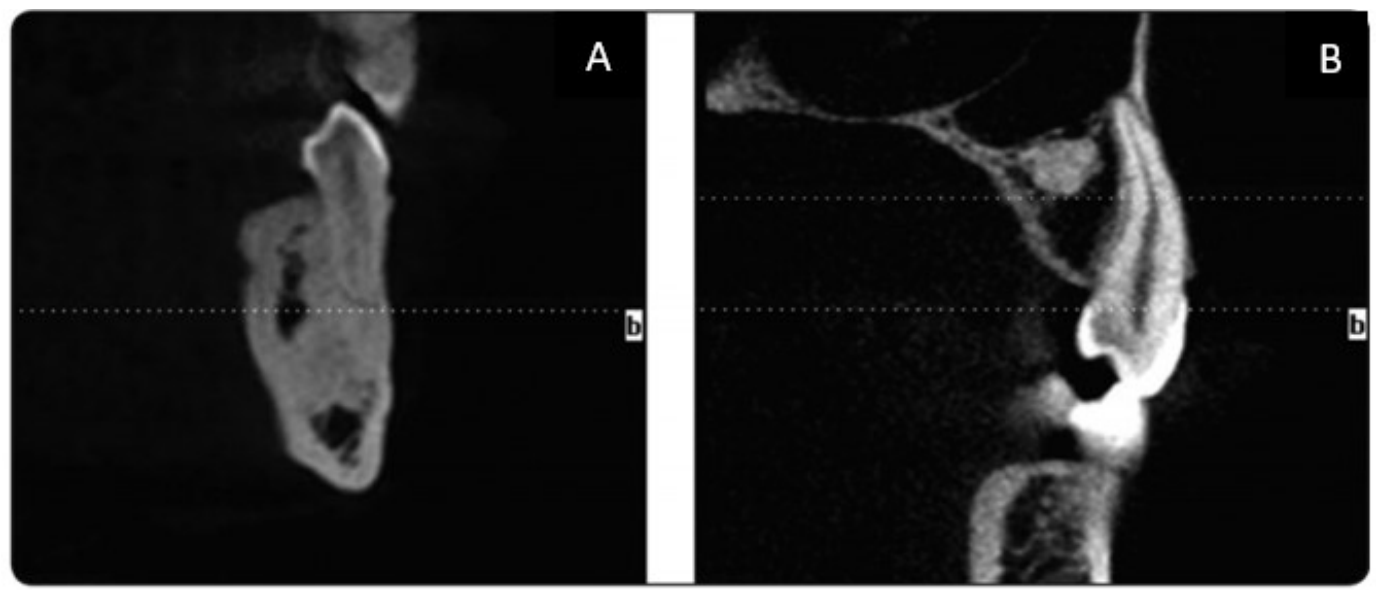

Gambar 5. Radiografi CBCT tampilan koronal menunjukkan idiopathic osteosclerosis pada mandibular (gambar A), dan pada rahang atas (gambar $B)^{10}$ 
radiolusen, pada benign cementoblastoma dan hipersementosis lesi tampak berkapsul. ${ }^{12}$ Torus mandibularis dan eksostosis dideskripsikan sebagai lesi radioopak single atau multiple pada permukaan periosteal dari rahang yang menunjukkan adanya pelebaran atau ekspansi tulang kortikal yang dapat terlihat pada pemeriksaan tomografi, namun pada idiopathic osteosclerosis tidak terjadi ekspansi tulang kortikal. ${ }^{2,12}$ Condensing osteitis bersifat asimptomatik, patologikal, dan terjadi perubahan yang persisten pada struktur tulang yang merupakan suatu respon stimulus inflamasi dari pulpa yang inflamasi atau nekrosis. Condensing osteitis terjadi pada gigi yang telah nekrosis atau non vital atau pada gigi yang mengalami karies dan tumpatan yang luas, serta terdapat pelebaran periodontal ligament space (PDLS), sedangkan idiopathic osteosclerosis terjadi pada gigi yang masih utuh (vital) atau gigi dengan karies atau tumpatan yang kecil, tidak terdapat adanya penyebab inflamasi, serta tidak menyebkan adanya perpindahan pada gigi disebelahnya., ${ }^{73}$ Pada radiografi $\mathrm{CBCT}$ perbedaan idiopathic osteosclerosis dengan condensing osteitis adalah idiopathic osteosclerosis terlihat well-defined (berbatas jelas), sedangkan condensing osteitis terlihat ill-defined (berbatas tidak jelas). ${ }^{5,17}$

Modalitas CBCT 3D sebagai pemeriksaan les sangat membantu dalam hal menentukan dan mengetahui bentuk, ukuran dan batas-batas lesi, memberikan data secara volumetrik, serta dapat mengidentifikasi lokasi yang tepat dan karakterisitik dari lesi osteosklerotik pada rahang. ${ }^{18,19}$ Selain itu, CBCT 3D digunakan sebagai pengganti CT konvensional karena dapat memberikan gambaran yang lebih detail dari bagian dalam tulang rahang. Modalitas CBCT 3D juga dapat digunakan untuk pemeriksaan kasus gigi impaksi, evaluasi pemasangan implant, evaluasi temporomandibular joint disorder, mengetahui lokasi gigi yang tidak erupsi, pemeriksaan resorbsi eksternal pada gig yang belum erupsi, pemeriksaan cleft palate, serta dapat digunakan untuk melakukan persiapan pembedahan/orthodonti kompleks dalam penaatalaksanaan maxillofacial skeletal abnormalities. ${ }^{12,20}$

\section{CONCLUSION}

Idiopathic osteosclerosis merupakan peningkatan kepadatan tulang yang terjadi pada area rahang atas atau rahang bawah terutama di sekitar akar gigi yang masih vital dan bersifat asimptomatik. Idiopathic osteosclerosis memiliki karakteristik berupa gambaran radiografi radioopak bebatas jelas (well-defined) yang tidak disertai dengan adanya inflamasi, neoplastik, atau penyakit sistemik, serta tidak menyebabkan pergeseran pada gigi disebelahnya. Radiografi cone beam computed tomography (CBCT) merupakan modalitas tiga dimensi (3D) yang dapat menjadi pilihan untuk mendapatkan gambaran dan karakteristik secara jelas dan detail pada kasus idiopathic osteosclerosis serta memberikan data dan ukuran lengkap dari lesi tersebut.

\section{ACKNOWLEDGMENTS}

None.

\section{FOOTNOTES}

All authors have no potential conflict of interest to declare for this article. Informed consent was obtained from the patient for being included in this case report.

\section{REFERENCES}

1. Mupparapu M, Shi KJ, Ko E. Differential diagnosis of periapical radiopacities and radiolucencies. Dent Clin North Am. 2020;64 (1):163-89.

2. Demir A, Pekiner FN. Idiopathic Osteosclerosis of the jaws in turkish subpopulation: cone-beam computed tomography findings. Clin Exp Heal Sci. 2019;117-23.

3. Gamba TO, Maciel NAP, Rados PV, da Silveira HLD, Arús NA, Flores IL. The imaging role for diagnosis of idiopathic osteosclerosis: a retrospective approach based on records of 33,550 cases. Clin Oral Investig. 2021;25(4):1755-65.

4. Ahmad NS, Yong J, Mei S, Ibrahim N, Fauzi AA, Megat $R$, et al. Asymptomatic radiopacity of mandible causing delayed orthodontic tooth movement : A Case Report. J Res Med Dent Sci. 2020;8(2):72-5.

5. Tsvetanov T. Mandibular idiopathic osteosclerosis or condensing osteitis. A Case Report. Int J Med Dent. 2020;24 (4):604-6.

6. Farhadi F, Ruhani MR, Zarandi A. Frequency and pattern of idiopathic osteosclerosis and condensing osteitis lesions in panoramic radiography of Iranian patients. Dent Res J (Isfahan). 2016;13(4):322-6.

7. Adisen M, Yilmaz S, Misirlioglu M, Nalcaci R. The evaluation of idiopathic osteosclerosis on panoramic radiographs with an investigation of lesion's relationship with mandibular canal by using cross-sectional cone-beam computed tomography images. J Oral Maxillofac Radiol. 2013;1(2):48.

8. Sisman $Y$, Ertas ET, Ertas H, Sekerci AE. The frequency and distribution of idiopathic osteosclerosis of the jaw. Eur J Dent. 2011 Aug;5(4):409-14.

9. Azizi Z, Mosafery H, Safi Y, Dabirzadeh S, Vasegh Z. Prevalence of idiopathic osteosclerosis on cone beam computed tomography images. J Dent Sch Shahid Beheshti Univ Med Sci. 2017;35(2):67-70

10. Zayet MK, Hassan AA. Assessment of idiopathic osteosclerosis in the jaws of the egyptian population using cone beam computed tomography. 2019;65:1397-401.

11. Li Z, Lai R, Feng Z. Case history report: cone beam computed tomography for implant insertion guidance in the presence of a dense bone island. Int J Prosthodont. 2016;29(2):186-7.

12. White SC, Pharoah MJ. Oral radiology principle and interpretation. 7th edition. St. Louis Missouri; 2014.

13. Sinnott PM, Hodges S. An incidental dense bone island: A review of potential medical and orthodontic implications of dense bone islands and case report. J Orthod. 2020;47(3):251 -6 .

14. Ledesma-Montes $\mathrm{C}$, Jiménez-Farfán $\mathrm{MD}$, Hernández-Guerrero JC. Idiopathic osteosclerosis in the maxillomandibular area. Radiol Medica [Internet]. 2019;124(1):27-33.

15. Verzak Z, Celap B, Modrić VE, Sorić P, Karlović Z. The prevalence of idiopathic osteosclerosis and condensing osteitis in Zagreb population. Acta Clin Croat. 2012 Dec;51 (4):573-7.

16. Rahman FUA, Epsilawati L, Pramanik F, Febriani M. Temuan insidental lesi radiopak asimptomatik pada pemeriksaan radiografi panoramik: laporan 3 kasus dan ulasan pustaka Dense Bone Island (DBI). J Radiol Dentomaksilofasial Indones. 2019;3(2):35

17. Silva BSF, Bueno MR, Yamamoto-Silva FP, Gomez RS, Peters 
OA, Estrela C. Differential diagnosis and clinical management of periapical radiopaque/hyperdense jaw lesions. Braz Oral Res. 2017;31:e52.

18. Chen $\mathrm{CH}$, Wang CK, Lin LM, Huang Y Der, Geist JR, Chen YK Retrospective comparison of the frequency, distribution, and radiographic features of osteosclerosis of the jaws between Taiwanese and American cohorts using cone-beam computed tomography. Oral Radiol. 2014;30(1):53-63.

19. Tie C, Zhi-ying Z. Cone beam computed tomography: a useful tool in diagnosis of bone ssland and implant insertion guidance. Omi J Radiol. 2012;01(02).

20. Whaites $E$, Drage $N$, Essentials of dental radiography and radiology. 5th edition. Elsevier; 2013. p.193. 